\title{
CERAMICĂ DE TIP TERRA SIGILLATA DESCOPERITĂ ÎN FORTIFICAȚII ROMANE DIN DACIA (INFERIOR) MALVENSIS
}

\author{
Mircea Negru, Alexandru Bădescu, Romeo Avram
}

\section{POTTERY OF TERRA SIGILLATA TYPE DISCOVERED IN ROMAN FORTS OF DACIA (INFERIOR) MALVENSIS}

\begin{abstract}
In the archaeological research that carried out in the last decades inside the Roman forts of Dacia (Inferior) Malvensis there were discovered some fragments of terra sigillata vessels. In this article, we present a small group of this kind of pottery found in the Central Fort of Romula and the castrum from Castra Traiana. The archaeological excavations belong to Cristian Vlădescu, Romeo Avram and Lucian Amon.

Types of vessels

The present terra sigillata fragments belong to Dragendorf 37 (nos. 3-4, 6-8) and Dragendorf 46 (nos. 1-2). The rest of the fragments are from the middle part of the vessels that cannot be certainly identified as shape.

\section{Pottery workshops}

Lezoux group (nos. 1-6, 9)

Some vessels made in this group are of Dragendorf 37 type and they have been decorated in Paternus II (nos. 4), Paternus II-III (no. 3) and Cinnamus (no. 5) styles. Other ones could be produced at Martres-de-Veyre (nos. 1-2).

The terra sigillata workshops from Martres-de-Veyre were dated in the $2^{\text {nd }}$ century AD, and those with Cinnamus, Paternus II and Paternus II-III decoration were produced between 140 and 195 AD.

\section{Rheinzabern group (nos. 7-8, 10-12)}

Some fragments belong to Dragendorf 37 type (nos. 7-8). The other ones are from the middle part of the vessels that cannot be certainly identified as shape. One of these belongs to Comitialis II decoration style (no. 10), the other one to Ianuarius II style (no. 11). First style was used in the Antonin Period, the second between the reigns of Antoninus Pius and Marcus Aurelius. The latest chronology of Rheinzabern workshops group is considered to be between 145 and 265 AD.
\end{abstract}

Keywords: Dacia Malvensis, terra sigillata, pottery, Castra Traiana, Romula, Lezoux, Rheinzabern Cuvinte cheie: Dacia Malvensis, terra sigillata, ceramică, Castra Traiana, Romula, Lezoux, Rheinzabern

Cercetările arheologice întreprinse în ultimele decenii în fortificațiile romane din Dacia (Inferior) Malvensis au fost inițiate de Cristian Vlădescu, apoi continuate de Romeo Avram şi Lucian Amon.

În cadrul săpăturilor arheologice întreprinse au fost descoperite, printre alte materiale arheologice, o serie de fragmente de vase de tip terra sigillata. Dintre cele rămase inedite încă, prezentăm un mic lot ce provine de la Castra Traiana şi Romula.

\section{Tipuri de vase}

Fragmentele de terra sigillata ce fac obiectul prezentului articol aparțin tipurilor Dragendorf 37 (nr. 3-4, 6-8) şi Dragendorf 46 (nr. 1-2). Altele nu pot fi atribuite cu certitudine, deoarece provin din partea mijlocie a vaselor (nr. 5, 9-12). 


\section{Ateliere de producție \\ Grupul Lezoux (nr. 1-6, 9)}

În cadrul grupului de producție ceramică de la Lezoux se pot identifica mai multe ateliere, dintre care cel mai important pare a fi cel omonim. Unele vase produse de grupul Lezoux sunt de tip Dragendorf 37 (nr. 3-5). Ele prezintă decor în stil Paternus II $(n r .3,4)$ şi Cinnamus (nr. 5).

Fragmentele de vase de tip Dragendorf 46 (nr. 1, 2) sunt mai apropiate tipologic de cele produse în cadrul atelierelor de la Martres-deVeyre. Vasele produse în această localitate pot fi distinse de cele de la Lezoux doar prin analize chimice de pastă (Romeuf 1986, p. 147). În cadrul atelierelor satelite celor de la Lezoux (Romeuf 1986, p. 146), pare să fi fost produs vasul de tip Dragendorf 18/31 (nr. 6).

Cronologic, atelierele de la Martres-deVeyre au funcționat în secolul al II-lea p.Chr., în timp ce vasele cu decorul în stilurile Cinnamus şi Paternus II, pot fi datate între 140 şi 195 p.Chr.

\section{Grupul Rheinzabern (7-8, 10-12)}

Fragmentele descoperite aparţin tipului Dragendorf 37 (nr. 7-8), respectiv nu pot fi atribuite unui tip (10-12), deoarece provin din partea mijlocie ale unor vase. Dintre ele unul poate fi atribuit stilului decorativ Comitialis II (nr. 10), iar altul stilului Ianuarius II (nr. 11). Stilul Ianuarius II a fost datat în perioada antoninilor, iar Comitialis II poate fi datat în perioada Antoninus Pius - Marcus Aurelius.

Perioada producției de terra sigillata în grupului de ateliere de la Rheinzabern a fost stabilită inițial la intervalul dintre al doilea sfert al secolului al II-lea p.Chr. şi anul 260 p.Chr. (Ricken 1948, p. VIII; Karnitsch 1955, p. 23). Ulterior, a fost propusă şi o încadrare cronologică care se rezumă la perioada anilor 145-265 p.Chr. (Lafon 1986, p. 185).

\section{Catalog}

1. Vas. Fragment. Ardere primară completă. Dimensiuni: $\mathrm{DG}=258 \mathrm{~mm}$. Buză arcuită la exterior. Fără decor. Castra Traiana, castrul roman, 1994, C. 16 AB, c. 9-10. MMN, fdi 279.

Tip Dragendorf 46
Centru de producție: Gallia centrală, grupul Lezoux

Analogii selective: Lezoux: (Vertet 1986, p. 140, fig. 1); Matres-de-Veyre (Romeuf 1986, p. 147)

Cronologie: sec. II p.Chr. (Vertet 1986, p. 139; Romeuf 1986, p. 147)

2. Cupă. Fragment. Ardere primară completă. Dimensiuni: $\mathrm{DG}=90 \mathrm{~mm}$. Corp tronconic. Buză răsfrântă. $\mathrm{Nu}$ prezintă decor. Castra Traiana, castrul roman, 1994, C 16B, c 11 -1,60 m, MMN, fdi 278.

Tip Dragendorff 46

Centru de producție: Gallia centrală, grupul Lezoux

Analogii selective: Lezoux: (Vertet 1986, p. 140, fig. 1); Matres-de-Veyre (Romeuf 1986, p. 147)

3. Vas. Fragment. Ceramică fină de culoare cărămizie acoperită cu vopsea roşie. Ardere primară completă. Ove alungite şi bastonaşe cu capete lățite. Linie orizontală perlată sub ove. Scenă erotică într-un medalion delimitat prin cercuri concentrice. Astragal. În partea dreaptă un panou delimitat de o linie verticală perlată, care în partea superioară are aplicată o mică rozetă plină cu şapte petale. În panou un personaj feminin cu bustul descoperit ține mâna dreaptă trecută peste bazin spre stânga. Castra Traiana, castrul roman, 1994, C 16A, c 9, 1,40/1,90 m. MMN, fdi 276.

Tip Dragendorff 37

Centru de producție: Gallia Centrală, grupul Lezoux

Stilurile Paternus II-III

Analogii selective: Enoşeşti-Acidava (Popilian, Ciucă 1993, p. 35, pl. II:36);

Observații: scena erotică este prezentă în stilul Paternus II (Rogers II, 1999, p. 25, pl. 78:25); elementele de separare ale panourilor sunt similare stilului Paternus III (Rogers, II, 1999, p. 25, pl. 80)

Cronologie: perioada 150-195 p.Chr. (Brukner 1981, p. 175);

4. Vas. Terra sigillata. Fragment. Ardere primară completă. Ove alungite şi bastonaşe cu capete lățite. Linie perlată sub ove. Se păstrează doar 
două ove. Castra Traiana, castrul roman, 1994, C 17, c 2. MMN, fdi 277.

Tip Dragendorff 37

Centru de producție: Gallia centrală, grupul Lezoux

Stilul Paternvs II

Analogii selective: Enoşeşti-Acidava (Popilian, Ciucă 1993, p. 34, pl. I:22); Novae (DimitrovaMilceva 2000, p. 15, 61, pl. 17:263); Lezoux, York, South Shields, Rouen, Augst (Oswald, Pryce 1966, p. 77, 151, pl. 30:91).

Cronologie: perioada 150-195 p.Chr. (Brukner 1981, p. 175); perioada 160-190 p.Chr. (Dimitrova-Milceva 2000, p. 61)

5. Castron. Fragment. Ceramică fină de culoare cărămizie. Ardere primară completă. Decorat pe interiorul bazei cu două şiruri concentrice realizate cu rotiţa şi două inele incizate. În cel mai mic se află ştampila (CINN)AMI. Castra Traiana, castrul roman, 1994, C 18/19, c 3 nivelul superior. MMN, fdi 280.

Centru de producție: Gallia centrală, grupul Lezoux

Cronologie: perioada 140-195 p.Chr. (Popilian 1976, 27)

Stilul Cinnamvs

Analogii selective: Oltenia (Popilian 1976, p. 27-30, pl. 14:8, 9); Buciumi (Chirilă, Gudea, Lucăcel, Pop 1972, p. 40, pl. 3:8); Lezoux (Oswald, Pryce 1966, p. 151, pl. 30:91); Carnuntum (Oswald, Pryce 1966, p. 373).

Cronologie: perioada 150-195 p.Chr. (Brukner 1981, p. 175)

6. Vas. Fragment. Ardere primară completă. Dimensiuni: $\mathrm{DG}=140 \mathrm{~mm}$. Corp tronconic. Buză scurtă rotunjită la exterior. Nu prezintă ove. $\mathrm{Nu}$ s-a păstrat alt decor. Romula, fortificația centrală, 1992, S 1 F, c 7 -1,50 m. MMN, fdi 198.

Tip Draggendorf 18/31

Centru de producție: Gallia centrală, grupul Lezoux

Analogii selective: Matres-de-Veyre (Romeuf 1986, p. 146)

Cronologie: sec. II p.Chr. (Romeuf 1986, p. 146)

7. Castron. Fragment. Ardere primară completă. Dimensiuni: $\mathrm{DG}=276 \mathrm{~mm}$. Corp tronconic arcuit. Buză rotunjită la exterior. Din şirul de ove s-au păstrat doar două. Nu prezintă bastonaşe. Romula, fortificaţia centrală, 1992, S 2 F, c 5. MMN, fdi 270.

Tip Draggendorf 37

Centru de productie: Rheinzabern

Analogii selective: Rheinzabern (Ricken 1948, Taf. 264:58); Romula (Popilian 1976, p. 32, pl. VIII, nr. 124);

Cronologie: al doilea sfert al secolului al II-lea - 260 p.Chr. (Ricken 1948, p.VIII; Karnitsch 1955 , p. 23)

8. Castron. Fragment. Ardere primară completă. Din şirul de ove s-au păstrat doar două. Nu prezintă bastonaşe. Romula, fortificaţia centrală, 1992, S 1 F, c 8, -1,05/1,80 m. MMN, fdi 266.

Tip Draggendorf 37

Centru de producție: Rheinzabern

Analogii selective: Rheinzabern (Ricken 1948, Taf. 264:55); Novae (Dimitrova-Milceva 2000, p. 63-64, pl. 18:293); Romula (Popilian 1976, pl. VIII:121).

Cronologie: al doilea sfert al secolului al II-lea - 260 p.Chr. (Ricken 1948, p. VIII; Karnitsch 1955, p. 23); epoca severilor (DimitrovaMilceva 2000, p. 63-64, nr. 293)

9. Vas. Fragment. Ceramică fină compactă de culoare cărămizie. Decor cu motive vegetale. Romula, fortificaţia centrală, 1992, S 2 F, c 17, $-1,60 \mathrm{~m}$. MMN, fdi 253.

Centru de producție: Gallia central-estică Analogii selective: Breçon (Stanfield, Simpson 1958, p. 136, pl. 64:22).

10. Bol. Fragment. Ardere primară completă. Décor cu arcade din segmente lineare. Între ele s-a păstrat parțial un personaj masculin cu sulița în mâna dreaptă, în poziţie de repaus. Romula, fortificația centrală, 1969. MMN, fdi 480 .

Centru de producție: Rheinzabern

Stilul Comitialis II

Analogii selective: Rheinzabern (Ricken 1948, Taf. 81:3; 82:10); Ricken, Thomas 2005, p. 91, pl. 81:4.

Cronologie: al doilea sfert al secolului al II-lea - 260 p.Chr. (Ricken 1948, p. VIII; Karnitsch 1955, p. 23); A. Pius - Septimius Severus (Brukner 1981, p. 175) 
11. Bol. Fragment. Ardere primară completă. Ove simple între două linii orizonatale. Decor cu colonete vegetale şi arcade din segmente lineare. Între colonete se află un motiv vegetal cu patru frunze. În interiorul arcadelor se observă o rozetă cu 13 proeminențe, respectiv un arbore. Romula, fortificația centrală, 1969. MMN, fdi 482.

Centru de producție: Rheinzabern

Stilul Ianuarius II

Analogii selective: Lauriacum (Karnitsch 1955, p. 72, Taf. 12:1, 12:5); Rheinzabern (Ricken 1948, Taf. 241:15, 16; 206:19; 204:6F); Sucidava (Popilian 1976, p. 166, pl. VIII:123). Cronologie: secolul al II-lea p.Chr. (Karnitsch 1955, p. 72)

12. Bol. Fragment. Ardere primară completă. Ove şi bastonaşe între două linii simple orizontale. Decor liber cu animale în alergare.
Dintre cele patru animale reprezentate pot fi cu siguranţă identificate o căprioară şi un cerb. În fața lor este reprezentat un arbore. Romula, fortificația centrală, 1969. MMN, fdi 481.

Centru de producție: Rheinzabern

Analogii selective: Rheinzabern, (Ricken 1948, Taf. 244:30, 34); Enoşeşti-Acidava (Popilian, Ciucă 1993, p. 46, pl. II:17)

Cronologie: al doilea sfert al secolului al II-lea p.Chr. - 260 p.Chr. (Ricken 1948, p. VIII; Karnitsch 1955, p. 23).

\author{
ABREVIERI \\ $\mathrm{C}=$ caseta \\ $\mathrm{c}=$ caroul \\ $\mathrm{DG}=$ diametrul gurii \\ $\mathrm{S}=$ secțiune \\ $\mathrm{fdi}=$ fond documentar, nr. inv. \\ MMN = Muzeul Militar Naţional
}

\section{BIBLIOGRAFIE}

Bet, Vertet 1986 - P. Bet, H. Vertet, Centre de production de Lezoux, în C. Bemont, J. P. Jacob (coord.), La terre sigillée gallo-romaine, Paris, 1986, p. 138-144.

Brukner 1981 - O. Brukner, Rimska keremika u Jugoslovenskom delu provincje Dolnje Pannonije, Beograd, 1981.

Chirilă, Gudea, Lucăcel, Pop 1972 - E. Chirilă, N. Gudea, V. Lucăcel, C. Pop, Das Römerlager von Buciumi, Cluj, 1972.

Dimitrova-Milčeva 2000 - A. Dimitrova-Milčeva, Terra sigillata und Dünnawandige keramic aus Moesia Inferior (Nordbulgarien), Sofia, 2000

Fidanovski 1990 - S. Fidanovski, Rimska keramika Ulpiane, Beograd, 1990.

Hermet 1934 - F. Hermet, La Graufsenque, Paris, 1934.

Karnitsch 1955 - I. Karnitsch, Die verzierte Sigillata von Lauriacum, Forschungen in Lauriacum, 3, Linz, 1955.

Lafon 1986 - X. Lafon, La fin des ateliers, Centre de production de Lezoux, în C. Bemont, J. P. Jacob (coord.), La terre sigillée gallo-romaine, Paris, 1986, p. 183-193.

Oswald, Pryce 1966 - An Introduction to the study of Terra Sigillata, London, 1969.

Popilian 1976 - G. Popilian, Ceramica romană din Oltenia, Craiova, 1976.

Popilian, Ciucă 1993 - Ceramica de tip terra sigillata de import descoperită la Enoşeşti-Acidava (jud. Olt), Arhivele Olteniei, SN, 8, 1993, p. 29-42.

Ricken 1948 - H. Ricken, Die Bilderschüsseln der Römischen Töpfer von Rheinzabern, Speyer, 1948.

Ricken, Thomas 2005 - H. Ricken, M. Thomas, Die Dekoratiosserien der Rheinzaberner Reliefsigillata, Bonn, 2005.

Rogers 1999 - G. B. Rogers, Poteries sigillées de la Gaule Centrale, II, Les potiers, Lezoux, 1999.

Romeuf 1986 - A.-M., Romeuf, Les Martres-de-Veyre, în C. Bemont, J. P. Jacob (coord.), La terre sigillée gallo-romaine, Paris, 1986, p. 145-152.

Stanfield, Simpson 1958 - J. A. Stanfield, G. Simpson, Central Gaulish Potters, London, 1958. 


\section{LIST OF ILLUSTRATIONS}

Fig. 1. Pottery of terra sigillata type discovered in Roman forts of Dacia (Inferior) Malvensis Fig. 2. Map of the archaeological sites with presented discoveries

\section{Mircea Negru}

Universitatea "Spiru Haret", Facultatea de Istorie mircea_negru_arch@yahoo.com

\section{Alexandru Bădescu}

Muzeul Național de Istorie a României

Calea Victoriei 12, 030026, Bucureşti, România alex_badescu@yahoo.com

\section{Romeo Avram}

0723312129

0749269440 